\title{
Unresectable Carcinoma
}

National Cancer Institute

\section{Source}

National Cancer Institute. Unresectable Carcinoma. NCI Thesaurus. Code C148124.

Carcinoma that is not amenable to surgical resection. 